\title{
Evaluation of BMI in obese adolescents at weight-loss camp with the Boy Scouts of America
}

\author{
Marsha B. Novick ${ }^{1+*}$, Erik Lehman ${ }^{2 \dagger}$ and Ronald J. Williams ${ }^{3 \dagger}$ \\ *Correspondence: mnovick@hmc.psu.edu

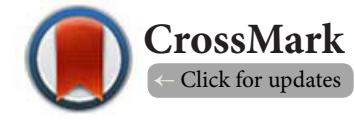 \\ ${ }^{\dagger}$ These authors contributed equally to this work. \\ 'Department of Pediatrics, Penn State Hershey Medical Center, USA. \\ ${ }^{2}$ Biostatistician Department of Public Health Sciences, Penn State Hershey Medical Center, USA. \\ ${ }^{3}$ Department of Pediatrics and Medicine, Penn State Hershey Medical Center, USA.
}

\begin{abstract}
Background: Summertime is particularly problematic for obese youth, as this unstructured time typically shows accelerated weight gain. We hypothesized that obese adolescents participating in a pilot summer camp program, developed in partnership with the Boy Scouts of America, would demonstrate significant weight loss and improvement of metabolic parameters.

Methods: Obese and overweight adolescent males between ages 13 and 18 were eligible for enrollment. BMI $\left(\mathrm{kg} / \mathrm{m}^{2}\right)$ and additional anthropometric and metabolic measurements were measured at the start and end of the 4 week camp.

Results: Thirteen participants enrolled and ten participants with the mean age of 16.1 years finished camp. Among these ten participants, BMI decreased by $9.1 \%\left(40.2 \pm 13.0 \mathrm{~kg} / \mathrm{m}^{2}\right.$ vs. $\left.36.5 \pm 12.0 \mathrm{~kg} / \mathrm{m}^{2} ; \mathrm{p}<0.001\right)$. Waist circumference decreased by $7.4 \%(48.4 \pm 9.6 \mathrm{~cm}$ vs. $44.9 \pm 9.4 \mathrm{~cm} ; \mathrm{p}<0.001)$, and fasting glucose levels decreased by $23.1 \%$ ( $84 \mathrm{mg} / \mathrm{dL}$ vs. $62 \mathrm{mg} / \mathrm{dL} ; \mathrm{p}=0.001)$.

Conclusions: BMI and metabolic parameters significantly improved after 4 weeks of camp. Partnering with the Boy Scouts of America is an innovative approach to creating a summer weight management camp for adolescents.
\end{abstract}

Keywords: Childhood obesity, weight loss treatment, blood pressure, hyperlipidemia

\section{Introduction}

Obesity is a global epidemic [1] and a public health crisis $[2,3]$. For overweight children, BMI increases more rapidly in summertime compared to the school year $[4,5]$.

The Penn State Hershey Children's Hospital in Hershey, Pennsylvania (USA) partnered with the Boys Scouts of America (BSA) to create an evidence-based weight-loss camp. The BSA organization promotes responsible citizenship through outdoor and educational activities. We hypothesized that adolescents participating in this pilot summer camp program would demonstrate significant weight loss and improvement of metabolic parameters.

\section{Methods}

Program overview

Penn State Hershey Children's Hospital partnered with the Hidden Valley Boy Scout Reservation in Loysville, Pennsylvania.
Camp staff consisted of two physicians, two BSA leaders, two dietitians, a psychologist, an exercise physiologist, one fitness leader, one cook, counselors and volunteers. A private donation and two grants funded all camp costs.

\section{Participants}

Obese (BMI $\geq 95$ th\%) adolescent males ages 13 to 18 seen within 4 months before camp at the Hershey Medical Center's Divisions of Pediatric Endocrinology and Pediatric Weight Management were eligible for enrollment. Exclusion criteria included uncontrolled mental health. No eligible participants were excluded.

Parents and campers consented to research with prior approval from the Penn State Hershey Medical Center IRB.

\section{Intervention}

Participants spent 4 uninterrupted weeks attending camp in 
Novick et al. Paediatrics and Health 2015,

July, 2008. Healthier options were added to the Boy Scout menu by the dietitians at $1800 \mathrm{kcals} /$ day.

Dietitians created an educational nutrition curriculum and held daily group sessions to discuss healthy eating habits and menu planning. Activity (1-3 hours a day) was led by a fitness leader and exercise physiologist and included swimming, team sports, hiking, canoeing, and archery. A psychologist ran weekly group meetings focused on behavior modification using cognitive behavior therapy.

The physicians and BSA leaders created the program and functioned to oversee the camper's safety. A physician recorded measurements of height, weight, resting pulse and BP weekly. Fasting insulin, glucose and lipid profiles were obtained $<1$ month prior to camp start and the last day of camp.

\section{Statistical analysis}

Categorical variables were summarized with percentages while continuous variables were summarized with means and standard deviations (Table 1). After checking the distributions of outcome variables, a linear mixed effects model for repeated measures analyzed the mean change in outcome variables from the start to the end of camp (Tables $\mathbf{2}$ and $\mathbf{3}$ ). This model allows data for all subjects to be used regardless of complete data. Model assumptions were determined to hold true by plotting the studentized residuals versus the predicted values as well as by using a normal QQ plot of
Table 1. Baseline characteristics of study sample $(\mathrm{N}=11)$.

\begin{tabular}{ll}
\hline Characteristic & Mean \pm SD or N (\%) \\
\hline Age (years), Mean \pm SD & $16.1 \pm 1.0$ \\
Weight start $(\mathrm{lbs})$, Mean \pm SD & $260.7 \pm 78.4$ \\
BMI start $\left(\mathrm{kg} / \mathrm{m}^{2}\right)$, Mean \pm SD & $40.2 \pm 13.0$ \\
\hline Ethnicity, \% & \\
\hline African American/Black & $5(45.5)$ \\
Asian & $1(9.0)$ \\
Caucasian & $4(36.5)$ \\
Hispanic/Latino & $1(9.0)$ \\
Residential category & -- \\
(based on RUC zip code), \% & $11(100)$ \\
Urban & \\
\hline Health insurance, \% & $6(55.5)$ \\
\hline Government & $5(45.5)$ \\
Non-government (Private) & $1(9.0)$ \\
Boy Scout Member &
\end{tabular}

the studentized residuals. Statistical significance was set at $p<0.05$. Statistical analyses used SAS software version 9.3 (SAS Institute, Cary, NC).

\section{Results}

Thirteen participants enrolled. Two campers left the first day, and one was dismissed after 2 weeks for behavior concerns.

Table 2. Comparisons of biometrics between start and end.

\begin{tabular}{|c|c|c|c|c|c|}
\hline \multirow[t]{2}{*}{ Biometric } & Start $(\mathrm{N}=11)$ & End $(\mathrm{N}=10)$ & $\Delta$ & $\% \Delta$ & \multirow[t]{2}{*}{ P-value ${ }^{*}$} \\
\hline & Mean $(95 \% \mathrm{CI})$ & Mean $(95 \% \mathrm{CI})$ & Mean $(95 \%$ CI $)$ & Mean $(95 \% \mathrm{CI})$ & \\
\hline Weight (lbs) & $260.7(208.0,313.4)$ & $238.0(189.7,286.3)$ & $-22.7(-27.8,-17.7)$ & $-8.7(-9.6,-7.8)$ & $<0.001$ \\
\hline $\operatorname{BMI}\left(\mathrm{kg} / \mathrm{m}^{2}\right)$ & $40.2(31.4,48.9)$ & $36.5(28.5,44.6)$ & $-3.6(-4.4,-2.9)$ & $-9.1(-10.2,-8.1)$ & $<0.001$ \\
\hline Waist circumference $(\mathrm{cm})$ & $48.4(41.9,54.8)$ & $44.9(38.5,51.2)$ & $-3.5(-4.2,-2.9)$ & $-7.4(-8.7,-6.1)$ & $<0.001$ \\
\hline Waist/Hip Ratio & $1.01(0.97,1.04)$ & $0.96(0.93,0.99)$ & $-0.05(-0.07,-0.02)$ & $-4.7(-6.9,-2.6)$ & 0.001 \\
\hline Resting pulse (bpm) & $100.9(89.0,112.9)$ & $79.6(72.3,87.0)$ & $-21.3(-36.5,-6.0)$ & $-18.6(-31.7,-5.5)$ & 0.011 \\
\hline Systolic blood pressure (mmHg) & $133.2(122.8,143.5)$ & $124.1(116.6,131.6)$ & $-9.1(-21.2,-3.0)$ & $-5.9(-14.3,2.6)$ & 0.125 \\
\hline Diastolic blood pressure (mmHg) & $74.4(66.3,82.4)$ & $69.1(62.1,76.1)$ & $-5.3(-13.5,3.0)$ & $-5.6(-17.4,6.3)$ & 0.186 \\
\hline
\end{tabular}

${ }^{*}$ P-value from linear mixed effects model for comparing the start to end means and the change $(\Delta)$ between them.

Table 3. Comparisons of fasting metabolic parameters between start and end.

\begin{tabular}{|c|c|c|c|c|c|}
\hline \multirow[t]{2}{*}{ Outcome } & Start $(\mathrm{N}=11)$ & End $(N=10)$ & $\Delta$ & $\% \Delta$ & \multirow[t]{2}{*}{ P-value ${ }^{\star}$} \\
\hline & Mean $(95 \% \mathrm{CI})$ & Mean $(95 \%$ CI $)$ & Mean $(95 \% \mathrm{CI})$ & Mean $(95 \% \mathrm{CI})$ & \\
\hline Insulin $(\mu \mathrm{IU} / \mathrm{mL})$ & $24.0(15.0,33.0)$ & $7.0(4.7,9.3)$ & $-17.0(-26.9,-7.1)$ & $-60.7(-80.3,-41.2)$ & 0.003 \\
\hline Glucose (mg/dL) & $83.6(75.5,91.7)$ & $62.4(57.6,67.1)$ & $-21.3(-31.5,-11.0)$ & $-23.1(-36.7,-9.5)$ & 0.001 \\
\hline Total cholesterol (mg/dL) & $167.8(139.8,195.9)$ & $130.2(105.6,154.7)$ & $-37.6(-47.0,-28.2)$ & $-22.5(-27.1,-18.0)$ & $<0.001$ \\
\hline LDL cholesterol (mg/dL) & $100.2(77.8,122.5)$ & $74.0(54.1,93.9)$ & $-26.2(-35.5,-16.9)$ & $-26.3(-35.0,-17.7)$ & $<0.001$ \\
\hline HDL cholesterol (mg/dL) & $44.6(37.7,51.5)$ & $40.9(32.0,49.8)$ & $-3.7(-10.5,3.1)$ & $-8.4(-24.5,7.7)$ & 0.250 \\
\hline Triglyceride (mg/dL) & $117.3(77.9,156.6)$ & $75.3(47.3,103.2)$ & $-42.0(-74.8,-9.2)$ & $-31.1(-59.9,-10.3)$ & 0.017 \\
\hline
\end{tabular}

${ }^{\star}$ P-value from linear mixed effects model for comparing the start to end means and the change $(\Delta)$ between them. 
Novick et al. Paediatrics and Health 2015,

Ten participants (mean age of 16.1) finished camp (Table 1). Medical problems included elevated blood pressure (6), hyperlipidemia (4), and hyperinsulinemia (6).

Among the eleven participants, the mean \pm SD pre-camp weight was $260.7 \pm 78.4 \mathrm{lbs}$., compared with the mean postcamp weight of $237.9 \pm 71.9$ lbs., a $8.7 \%$ reduction $(p<0.001)$ (Table 2). The mean \pm SD pre-camp BMI was $40.2 \pm 13.0 \mathrm{~kg} / \mathrm{m}^{2}$ compared with the mean post-camp BMI of $36.5 \pm 12.0 \mathrm{~kg} / \mathrm{m}^{2}$, a $9.1 \%$ reduction $(p<0.001)$.

Systolic and diastolic blood pressures, waist circumference, waist-to-hip ratio and resting pulse significantly decreased (Table 2). Waist circumference decreased $7.4 \%(48.4 \pm 9.6 \mathrm{~cm}$ vs. $44.9 \pm 9.4 \mathrm{~cm} ; \mathrm{p}<0.001)$.

Insulin, glucose, total cholesterol, LDL cholesterol and triglycerides significantly decreased (Table 3). Fasting glucose decreased 23.1\% ( $84 \mathrm{mg} / \mathrm{dL}$ vs. $62 \mathrm{mg} / \mathrm{dL} ; \mathrm{p}=0.001$ ). At camp's end, $66 \%(4 / 6)$ with elevated blood pressure, $75 \%$ (3/4) with hyperlipidemia, and all with hyperinsulinemia (6/6) normalized.

\section{Discussion}

Summertime is problematic for obese youth, as this unstruc tured time typically shows accelerated weight gain. This pilot study demonstrates that collaboration with the BSA is an effective strategy for implementing summertime weight loss for adolescents.

Our findings of reduced weight, BMI [6-8] and blood pressure [9] are consistent with other previously published reports.

To our knowledge, this is the first published report of improved waist circumference, waist-to-hip ratio, insulin and hyperlipidemia, suggesting a unique contribution to the literature.

Previous studies show sustainable weight loss is possible after camp; [10-12] however, further study is needed regarding long-term health outcomes and the feasibility of wide scale implementation. Major limitations of this study include a small sample size with lack of control group and follow-up after camp.

\section{Conclusion}

Physicians should consider networking with community organizations, like the BSA, to create desired summer weightloss programs.

\section{List of abbreviations}

BSA: Boy Scouts of America

BMI: Body mass index

BP: Blood pressure

HDL: High density lipoprotein

LDL: Low density lipoprotein

Competing interests

The authors declare that they have no competing interests.

Authors' contributions
\begin{tabular}{|l|c|c|c|}
\hline Authors' contributions & MBN & EL & RJW \\
\hline Research concept and design & $\checkmark$ & -- & $\checkmark$ \\
\hline Collection and/or assembly of data & $\checkmark$ & -- & $\checkmark$ \\
\hline Data analysis and interpretation & $\checkmark$ & $\checkmark$ & $\checkmark$ \\
\hline Writing the article & $\checkmark$ & $\checkmark$ & $\checkmark$ \\
\hline Critical revision of the article & $\checkmark$ & $\checkmark$ & $\checkmark$ \\
\hline Final approval of article & $\checkmark$ & $\checkmark$ & $\checkmark$ \\
\hline Statistical analysis & $\checkmark$ & $\checkmark$ & $\checkmark$ \\
\hline
\end{tabular}

Acknowledgement and funding

We would like to thank Jeanne and Edward Arnold, Children's Miracle Network, and Friends and Faculty of Penn State Milton S. Hershey Medical Center for their generous donations to sponsor Camp LION. Thank you to Jack Carr, Kevin Gill and Jack Dalton of the Hidden Valley Boy Scout Reservation of Perry County, Pennsylvania, Susan Reeves, RD, Caroline Claus, RD, Kathy Simmons, Scott Makibbin, Andrea Gorman, PhD, Barbara Ostrov, MD, Gill Pak, Kristen Shaver, and Carlos Juan Sandoval. A special thanks to Danielle Ehrgood and lan Paul, $M D$, and the campers, parents, and volunteers of Camp LION.

Publication history

Editors: Charles L. Schleien, Hofstra North Shore-LIJ School of Medicine, USA.

Mario A. Cleves, Arkansas Children's Nutrition Center, USA. Mohamed Ibrahim Ali Omer, University of West Indies, Trinidad and Tobago.

Senior Editor: Victor C. Strasburger, UNM School of Medicine, USA. Received: 05-Dec-2014 Final Revised: 05-Jan-2015

Accepted: 11-Feb-2015 Published: 19-Feb-2015

\section{References}

1. World Health Organization (WHO): Obesity and overweight. 2008. | Website

2. Wang $Y$, Beydoun MA, Liang L, Caballero B and Kumanyika SK. Will all Americans become overweight or obese? estimating the progression and cost of the US obesity epidemic. Obesity (Silver Spring). 2008; 16:2323-30. | Article | PubMed

3. Wang $Y$ and Beydoun MA. The obesity epidemic in the United States--gender, age, socioeconomic, racial/ethnic, and geographic characteristics: a systematic review and meta-regression analysis. Epidemiol Rev. 2007; 29:6-28. | Article | PubMed

4. von Hippel PT, Powell B, Downey DB and Rowland NJ. The effect of school on overweight in childhood: gain in body mass index during the school year and during summer vacation. Am J Public Health. 2007; 97:696-702. | Article | PubMed Abstract | PubMed Full Text

5. Moreno JP, Johnston CA and Woehler D. Changes in weight over the school year and summer vacation: results of a 5-year longitudinal study. J Sch Health. 2013; 83:473-7. I Article I PubMed

6. Huelsing J, Kanafani N, Mao J and White NH. Camp jump start: effects of a residential summer weight-loss camp for older children and adolescents. Pediatrics. 2010; 125:e884-90. I Article I PubMed

7. Gately PJ, Cooke CB, Barth JH, Bewick BM, Radley D and Hill AJ. Children's residential weight-loss programs can work: a prospective cohort study of short-term outcomes for overweight and obese children. Pediatrics. 2005; 116:73-7. I Article | PubMed

8. Kelly KP and Kirschenbaum DS. Immersion treatment of childhood and adolescent obesity: the first review of a promising intervention. Obes Rev. 2011; 12:37-49. | Article | PubMed Abstract | PubMed Full Text 
Novick et al. Paediatrics and Health 2015,

9. Wong WW, Abrams SH, Mikhail C, Terrazas NL, Wilson TA, Arceo D, Mrowczynski PK, King KL, Stansel AD, Albright AN, Barlow SE, Brown KO, Brown JD and Klish WJ. An innovative summer camp program improves weight and self-esteem in obese children. J Pediatr Gastroenterol Nutr. 2009; 49:493-7. I Article I PubMed

10. Kirschenbaum DS. Weight-loss camps in the U.S. and the immersion-tolifestyle change model. Childhood Obesity. 2010; 6:318-323. | Article

11. Kirschenbaum DS, Craig RD, Pecora Kelly K and Germann JN. Treatment and innovation: description and evaluation of new programs currently available for your patients. Immersion Programs for Treating Pediatric Obesity: Follow-up evaluations of wellspring camps and academy of the sierras, a boarding school for overweight teenagers. Obesity Management. 2007; 3:261-266. | Article

12. Gately PJ, Cooke CB, Butterly RJ, Mackreth P and Carroll S. The effects of a children's summer camp programme on weight loss, with a 10 month follow-up. Int J Obes Relat Metab Disord. 2000; 24:1445-52. | Article | PubMed

\section{Citation:}

Novick MB, Lehman E and Williams RJ. Evaluation of BMI in obese adolescents at weight-loss camp with the Boy Scouts of America. Paediatr Health. 2015; 3:1. http://dx.doi.org/10.7243/2052-935X-3-1 